\title{
Social goals of Filipino adolescents: Do they contribute to
} student life satisfaction?

Ouano, Jerome A. $\bowtie$

Department of Psychology, Xavier University-Ateneo de Cagayan, Cagayan de Oro, Philippines (ouano_j@yahoo.com)

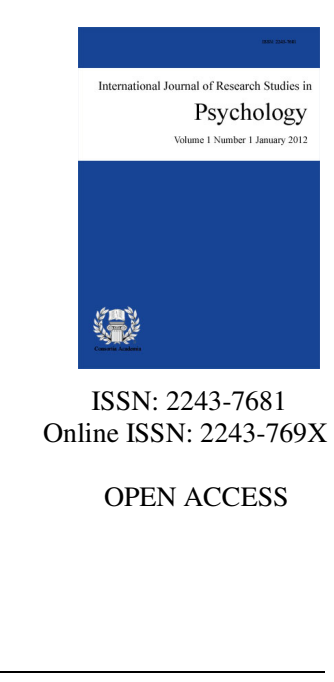

Pinugu, Jasmine Nadja

Mapua Institute of Technology,

Manila, Philippines (jasmine.pinugu@gmail.com)

\section{Abstract}

Premised on positive psychology and the social rootedness of students' motivation, the study explored the effects of social goals on student life satisfaction. Using a predictive cross-sectional non-experimental design, the five social goals from the formulation of Dowson and McInerney (2004) were tested as predictors of the five dimensions of Huebner's (2001) student life satisfaction among 302 college students who responded to self-report questionnaires. Results provided evidence for the potential contribution of social goals on student life satisfaction. Social affiliation goal predicted student's satisfaction with friends, school, living environment, and self, but not with family. Social responsibility goal predicted satisfaction with family, school, living environment, and self, but not with friends. Social status goal predicted satisfaction with family, friends, and self, but not with school and living environment. Social approval and social concern goals predicted all the dimension of student life satisfaction. Discussion centers on how the students' endorsement of each social goal contributes to their life satisfaction.

Keywords: Filipino; positive psychology; social goals; student life satisfaction 


\section{Social goals of Filipino adolescents: Do they contribute to student life satisfaction?}

\section{Introduction}

The advent of positive psychology has paved the way for the investigation of life satisfaction and well-being of individuals, veering away from the traditional psychology of focusing on disorders (Seligman \& Csikszentmihalyi, 2000). More than the absence of symptoms and pathology, well-being encompasses a wide range of cognitive, affective, and behavioral components that contribute to a person's degree of life satisfaction. Well-being allows people to grow and flourish throughout their lives. It is rooted in having good relationships with friends, family, and other significant authority figures that serve as positive role models, and in the existence of enhancing social institutions (Park, 2004).

Positive Psychology holds that people pursue happiness as one of their most cherished goals (Seligman, Steen, Park, \& Peterson, 2005). In their pursuit, people derive their resources from their virtues and character strengths by tapping their cognitive strengths (e.g., wisdom and knowledge) to acquire and apply knowledge; utilizing emotional strengths (e.g., courage) to accomplish and fulfill tasks despite adversities that come their way; engaging their interpersonal strengths (e.g., humanity) to care for others; using their civic strengths (e.g., justice) to promote a healthy community; exercising temperance to regulate and protect the self from excess; and pursuing transcendence to cultivate personal meaning and connection with a larger universe (Seligman et al., 2005). Virtues and character strengths are acquired through social experiences and their impact on well-being is dependent on the social context in which they operate (McNulty \& Fincham, 2012). These virtues and strengths are associated with living in wellness, contentment, and satisfaction in the past, flow and happiness at present, and hope and optimism in the future (McNulty \& Fincham, 2012). They can also be a result of the interplay of personal traits and social environment where of some the socially important purposes for behaving in certain ways are integrated in the person's sense of self, and activate the motivational processes for engaging in various tasks. These motivational processes can enhance and sustain well-being and happiness (Lyubomirsky, 2001).

There is a substantial account for motivation playing a key role in achieving and sustaining wellness, particularly in the literature on achievement motivation (e.g., Burton, Lydon, D’Alessandro, \& Koestner, 2006; Ryan \& Deci, 2000). Achievement motivation may increase the students' capacity for growth, which enhances their well-being. And, in turn, their well-being fosters positive and healthy development. Most of the reports, so far, point to intrinsic and personal academic dimensions of motivation as beneficial to students' well-being. There is scant evidence reported in the literature on whether the same pattern of relationship may be found with socially oriented motivations, or those motivations of students that are being catalyzed within the students' significant social relationships (Chang \& Wong, 2008). In doing schoolwork, students may want to to learn and achieve competence in order to enhance their sense of acceptance and belongingness to their peer groups. Other students may also be academically motivated by a sense of obligation and duty to meet some expectations set by other people on them, or a concern to help others in their academic and personal development. All of these academic motivations are socially-oriented because the purposes of their actions toward academic achievement are rooted in their social relationships and in the context within which the students live (Dowson \& McInerney, 2001).

The emerging literature on socially-oriented motivation describes the salience of social goals in the students. Social goals are students' social reasons for achieving academically (Blumenfeld, 1992; Urdan \& Maehr, 1995). Students endorse these social goals as they try to achieve in academic situations. In Downson and McInerney's (2004) formulation, these goals include social affiliation, or wanting achieve to enhance a sense of social belonging with friends; social approval, or wanting to achieve to gain the approval of teachers and parents; social concern, or wanting to achieve to help friends and other students; social responsibility, or wanting to achieve to fulfill role obligations; and social status, or wanting to achieve to get a good job in the future and earn 
wealth. Social goals are not only correlated but also relatively distinct in terms of their specific cognitive, affective, and behavioral components, and therefore, they are multidimensional. In an earlier study, some of these goals were found among Anglo-Australian, and Northeast Asian- and Southeast Asian-Australian students (Dowson \& McInerney, 2001). Recently, social goals have been studied in the Philippines, and found to be present among Filipino students (e.g., King \& Watkins, 2011; Ouano, 2012).

Social goals have yet to gain a considerable amount of attention in the line of research that attempts to link motivation with various dimensions of well-being, especially in collectivist societies where social relationships play an important role in shaping the students' behavior and life satisfaction. In these societies, students construct their achievement goals with reference to the norms and values that are socially negotiated. Although it is very likely that these students endorse both personally derived goals and socially derived goals, it is expected that they draw more motivational resources from the latter type of goals. They may even downplay their endorsement of the personally derived goals and prioritize the socially derived goals. Triandis (1995) found that students feel more compelled to reach the externally-derived goals even when they realize that these goals are difficult to achieve. Whereas, if the goals are self-imposed, students may easily downgrade these goals when they find them too difficult to achieve. It means that student strive to adjust their motives in order to properly position themselves in a desirable space in relation to others, which is an important characteristic of persons who hold an interdependent view of the self (Markus \& Kitayama, 1991). The importance placed on social connectedness among people in collectivist societies is likely to make socially derived motivations more salient and functional in attaining success and life satisfaction.

Student life satisfaction is contextualized within the achievement situations where students strive to achieve academically in order to be associated with their peers, to please their parents or teachers, to extend academic and personal help to others, to fulfill social role obligations, and be able to be gainfully work in future. These goals provide them with greater opportunities to build a strong social network, thereby enhacing life satisfaction. It is the importance of this social connectedness in the lives of Filipino students that motivated the present study to seek an empirical evidence of the potential social motivational sources of their life satisfaction. Because social goals are salient among Filipino students, the present study examined the predictive utility of these goals on the students' life satisfaction. Considering that social goals are multidimensional, it was also important to specifically explore how each goal can serve as a potential source of satisfaction.

\section{Methods}

\subsection{Participants}

A total of 302 college students from two private universities in the Northern Mindanao Region of the Philippines gave their informed consent to participate in the study. Among them were 126 (42\%) males and 176 (58\%) females. The participants were in their regular second year of studies and in the preliminary period or the first qurter of the semester at the time of data gathering. Participants" ages ranged from 16 to 19 (M=17.51, $\mathrm{SD}=.79)$.

\subsection{Measures}

Social goals were measured using the Social Goals subscale of the Social Goal Orientation and Learning Strategies Survey (GOALS-S), developed by Dowson and McInerney (2004). It is a 30-item scale for social affiliation, social approval, social concern, social responsibility, and social status goals. The participants expressed their judgment of how much each statement is true of them, using a 5-point scale from 1=Not at all true of me, to $5=$ Very true of me. Cronbach alpha of the 5 social goals ranged from .88 to .91 .

Life satisfaction was measured using the 40-item Multidimensional Students' Life Satisfaction Scale developed by Huebner (2001) to assess student life satisfaction with family, friends, school, self, and living 
environment. Because the psychometric properties of the original scale were derived from elementary and high school students, the present study reexamined the latent structure of student life satisfaction among adolescent participants through Exploratory Factor Analysis. Using Maximum Likelihood Extraction method with Varimax rotation, a 5-factor solution, and factor loading $>.40$, the same factors were found as in the original scale, with Eigenvalues $>1.0$, explaining $48.36 \%$ of the variance. All 9 items on friends loaded significantly in one factor, and all 8 items on school loaded together in one factor. Only 5 out of 7 items on family, only 6 out of 7 items on self, and only 5 out of 9 items on living environment loaded together respectively. Other items did not load significantly on any factor. Finally, student life satisfaction was measured in terms of satisfaction with family (5 items), friends (9 items), school (8 items), self (6 items), and living environment (5 items). Cronbach alpha of the 5 subscales ranged from .79 to .88 .

\subsection{Data Analysis}

Considering that social goals are sensitive to social contexts, the data from two schools were first inspected for homogeneity of variance on each of the five social goals. After meeting the homogeneity assumption, the data were merged for analysis. Initially, descriptive analysis and zero-order correlations were carried. Then for the main analysis, the five social goals were used as predictors of each of the five dimensions of student life satisfaction in the Multiple Regression analysis.

\section{Results}

It was the aim of the study to find out if social goals contribute to student life satisfaction. To see if these social goals could exert predictive effects on life satisfaction, preliminary analysis were first carried to examine the variables under study. Table 1 shows the descriptive indices of the dimensions of social goals and of students' life satisfaction.

\section{Table 1}

Means, Standard Deviations, and Scale Reliabilities

\begin{tabular}{lccc}
\hline \multicolumn{1}{c}{ Variable } & $M$ & $S D$ & Cronbach alpha \\
\hline Social goals & & & \\
$\quad$ Affiliation & 3.06 & 1.05 & .90 \\
Approval & 2.80 & 0.99 & .89 \\
Concern & 3.08 & 1.00 & .90 \\
Responsibility & 3.05 & 1.01 & .91 \\
$\quad$ Status & 2.92 & 1.02 & .88 \\
Life satisfaction & & & \\
Family & 2.95 & 1.07 & .83 \\
Friends & 2.96 & 0.95 & .87 \\
School & 2.63 & 0.97 & .85 \\
Self & 3.05 & 1.04 & .88 \\
Living environment & 3.04 & 0.98 & .79 \\
\hline
\end{tabular}

It can be recalled that the theorizing on social goals also highlights the multidimensionality of students' social academic reasons, in the assumption that, although all these dimensions draw from the students' social relationships and thus share some variance due to this similarity, each dimension is also relatively distinct from one another because the motives are derived from distinct social processes. Similarly, life satisfaction is multidimensional, and its dimensions are both relatively similar to and distinct from one another. To check for their possible multidimensional nature, a zero-order correlation was performed for the dimensions of social goals and of student life satisfaction. As shown in Table 2, all the dimensions of social goals are positively correlated. The same is true for the dimensions of students' life satisfaction. These results suggest the coexistence of the dimensions of social goals as well as of student life satisfaction. 


\section{Table 2}

Correlations of Social Goals and Life Satisfaction

\begin{tabular}{|c|c|c|c|c|c|c|c|c|c|}
\hline Variables & 1 & 2 & 3 & 4 & 5 & 6 & 7 & 8 & 9 \\
\hline 1. Affiliation & --- & & & & & & & & \\
\hline 2. Approval & $.70 * *$ & --- & & & & & & & \\
\hline 3. Concern & $.48 * *$ & $.36 * *$ & --- & & & & & & \\
\hline 4. Responsibility & $.52 * *$ & $.44 * *$ & $.70 * *$ & --- & & & & & \\
\hline 5. Status & $.45^{* *}$ & $.60 * *$ & $.31 * *$ & $.39 * *$ & --- & & & & \\
\hline 6. Family & .09 & $.18 *$ & $.85 * *$ & $.84 * *$ & $.82 * *$ & --- & & & \\
\hline 7. Friends & $.77 * *$ & $.55^{* *}$ & $.88 * *$ & .07 & $.70 * *$ & $.40 * *$ & --- & & \\
\hline 8. School & $.62 * *$ & $.82 * *$ & $.86 * *$ & $.18^{*}$ & .09 & $.36 * *$ & $.55 * *$ & --- & \\
\hline 9. Self & $.18^{*}$ & $.16^{*}$ & $.84 * *$ & $.85^{* *}$ & $.87 * *$ & $.48 * *$ & $.47 * *$ & $.49 * *$ & --- \\
\hline 10. Living environment & $.56 * *$ & $.54 * *$ & $.87 * *$ & $.83 * *$ & .08 & $.42 * *$ & $.30 * *$ & $.61 * *$ & $.35 * *$ \\
\hline
\end{tabular}

To explore how social goals exert predictive effects on student life satisfaction, all the five social goals were entered in the multiple regression equation to find out the net effect of each goal on every dimension of student life satisfaction. Results in Table 3 show that all types of social goals predicted students' satisfaction with self. Some of these goals, however, did not consistently predict the other dimensions of life satisfaction. Both Social approval and social concern goals predicted satisfaction with family and friends. Social affiliation predicted satisfaction with friends but not with family. Social responsibility and social status predicted satisfaction with family, but not with friends.

Table 3

Regression results on Satisfaction with Family, Friends, and Self

\begin{tabular}{|c|c|c|c|c|c|c|c|c|c|}
\hline \multirow[t]{2}{*}{ Predictors } & \multicolumn{3}{|c|}{ Family $^{1}$} & \multicolumn{3}{|c|}{ Friends $^{2}$} & \multicolumn{3}{|c|}{ Self $^{3}$} \\
\hline & $\beta$ & SE $\beta$ & $\mathrm{T}$ & $\beta$ & SE $\beta$ & $\mathrm{t}$ & B & SE $\beta$ & $\mathrm{t}$ \\
\hline Affiliation & .01 & .05 & 0.06 & .32 & .06 & $4.98 * * *$ & .13 & .06 & $2.10^{*}$ \\
\hline Approval & .16 & .06 & $2.59 *$ & .15 & .05 & $3.16 * *$ & .13 & .05 & $2.29 *$ \\
\hline Concern & .35 & .05 & $6.49 * * *$ & .35 & .05 & $5.81 * * *$ & .26 & .06 & $4.24 * * *$ \\
\hline Responsibility & .15 & .04 & $3.35 * * *$ & .09 & .07 & 1.35 & .26 & .05 & $3.67 * * *$ \\
\hline Status & .31 & .06 & $5.31 * * *$ & .05 & .06 & 0.79 & .21 & .06 & $5.67 * * *$ \\
\hline
\end{tabular}

The same social goals were entered in the regression equation to test for their specific effects on the environment-related aspects of student life satisfaction, and results in Table 4 indicate that social affiliation, social approval, social concern, and social responsibility goals predicted satisfaction with school and living environment. Social status goal, on the other hand, showed no significant effect on these two aspects of students' life satisfaction. 
Ouano, J. A. \& Pinugu, J. N.

Table 4

Regression results on Satisfaction with School and Living Environment

\begin{tabular}{|c|c|c|c|c|c|c|}
\hline \multirow[t]{2}{*}{ Predictors } & \multicolumn{3}{|c|}{ School $^{1}$} & \multicolumn{3}{|c|}{ Living Environment $^{2}$} \\
\hline & B & $\mathrm{SE} \beta$ & $\mathrm{t}$ & $\beta$ & SE $\beta$ & $\mathrm{t}$ \\
\hline Affiliation & .18 & .06 & $2.79 * *$ & .21 & .06 & $3.38 * * *$ \\
\hline Approval & .21 & .05 & $4.30 * * *$ & .20 & .06 & $3.50 * * *$ \\
\hline Concern & .36 & .06 & $5.45^{* * *}$ & .34 & .06 & $5.63 * * *$ \\
\hline Responsibility & .12 & .06 & $2.08 *$ & .19 & .05 & $4.01 * * *$ \\
\hline Status & .09 & .06 & 1.60 & .04 & .06 & 0.72 \\
\hline
\end{tabular}

Note. ${ }^{1} \mathrm{~F}(5,296)=337.06$, Adjusted R2 $=.85, \mathrm{p}<.001$

${ }^{2} \mathrm{~F}(5,296)=385.07$, Adjusted R2 $=.86, \mathrm{p}<.001$

$* * * \mathrm{p}<.001 ; * * \mathrm{p}<.01 ;{ }^{*} \mathrm{p}<.05$

In sum, the results in Tables 3 and 4 illustrate how specific types of social goals contributed to specific aspects of student life satisfaction. Social affiliation is associated with students' satisfaction with friends, self, school, and living environment, but not with family. Social approval and social concern goals are associated with satisfaction with family, friends, self, school, and living environment. Social responsibility is associated with students' satisfaction with family, self, school and living environment, but not with friends. Social status goal is associated with students' satisfaction with family and self, but not with friends, school, and living environment.

\section{Discussion}

The present study is an attempt to explore the potential contribution of social goals to the student life satisfaction, drawing from positive psychology's main argument that the improvement of people's condition does not only come from the transformation of negative impulses, but more importantly from their virtues and character strengths from which a variety of motivations take shape. Social goals held by Filipino adolescent students are motivational resources that contribute to various aspects of their life satisfaction.

Students' satisfaction with their family can take sources from their social approval goals. Their desire to please their significant authority figures generally gives a feeling of being connected to them. When students want to achieve academically in order to please or be praised by their parents and teachers, their effort may gradually strengthen their relationship with these authority figures. Similarly, when these students are motivated by the desire to fulfill role obligations, or to help others, their effort becomes instrumental to the development of responsible behavior, which is very well appreciated by parents and teachers at this time in the students' lives as adolescents. The praises and appreciation students gain from pleasing their significant authority figures can enhance a sense of affirmation and social connectedness, thus increasing the feeling security.

Students who think of their future and engage academically in order to get a gainful job in the future may feel closely connected with their families. Among Filipinos, work-related ambitions are generally drawn from family situations in which family members strive to have a good future in order to help their families improve their living condition and live a better life. With basis on Markus and Kitayama's (1991) explanation about how people in interdependent society think, feel, and act, it is plausible to assume that Filipino students being interdependent are likely to formulate their social status goal with reference to their families. And these ambitions not only give hope to the self but also to the family, and produce in the students a sense of belonging and a feeling of closeness to their family.

Satisfaction with friends may also take sources from social affiliation goal in that students' motive to be in solidarity with their groups in school, especially their academic groups, can enhance relationship with group members and friends. Within their groups, students' social concern are also important in maintaining social 
solidarity because when they help their friends, relationships within groups are strengthened (Dowson \& McInerney, 2001). Their feeling of connectedness within their social groups can build a sense of belonging and security. Satisfaction with friends may be further sustained when students endorse social approval goal inasmuch as when the significant authority figures are pleased, or when praises from them are gained, students may feel they are being indirectly permitted to be with their friends.

Environment related satisfaction also draws from social affiliation, social approval, social concern, and social responsibility goals. These goals provide resources for social connectedness such that students strive to achieve in academic situations in order to promote solidarity with friends, gain the appreciation of their parents and teachers, assist friends who need help, and meet social expectations or fulfill obligations. It is very likely that these dimensions of social goals facilitate the creation of stronger social network where students enjoy their harmonious relationship with friends or peers. Similarly, students' success in trying to adhere to the expectations of the authority figure may recruit a happy feeling. This conjecture can be loosely gleaned from the previous findings that students' dependence on the teacher is predictive of positive emotions (Ouano, 2011). This implies that students may feel good in school and in their living environment when they are able to do what they are asked to do because they gain the appreciation of their significant authority figure. Enhanced relationships with friends and authority figure give a sense of community within the broad social environment, and therefore, students feel more satisfied.

Satisfaction with the self is influenced by all dimensions of social goals. When students endorse social affiliation goals, they take on a desire to earn a sense of belonging and solidarity with academic groups by engaging academically, which is more likely to improve their academic efficacy (Dowson \& McInerney, 2001). Their motive to do schoolwork in order to help their friends improves the bonding and solidarity within academic groups, which also makes them feel more socially secured. Likewise, their motive to have a gainful and sustainable job in the future gives them a sense of hope, personal meaning, and importance. Moreover, when students endorse social responsibility goal in doing academic tasks, there is a greater opportunity to earn a sense of pride from being able to contribute to the completion of task or do something to fulfill communal role expectations. Having performed socially supportive roles earn for the students an increased self-worth, a claim that was reported in the earlier work of Dowson and McInerney (2001). Even simple compliance to social expectations, usually operating in introjected regulation of external demand, can enhance the ego of the person (Ryan \& Deci, 2000). The same ego enhancement can happen when students are able to please their parents and teachers through their academic engagement.

It can be gleaned from the results of the present study that Filipino adolescent students endorse social goals, and these goals, in general, contribute to the students' life satisfaction. It was further observed that the results on social concern showed consistently larger effect size. This may suggest that the motive to do schoolwork in order to help other people gives a stronger sense of self. Students who hold this goal may feel a greater power to do something for others, and their actions toward others are usually aligned with what others also need, thus making their actions more socially relevant. This is consistent with the findings of Mast, Jonas, and Hall (2009) that power is associated with interpersonal sensitivity where persons with high sense of power do infer the thoughts and feelings of others than those with low power. This subjective feeling of power can also be functionally related to life satisfaction because it makes the person wade through dilemmas more consciously (Lammers \& Stapel, 2009), thereby increasing life's quality.

Finally, the present study also affirms the argument that both individualism- and collectivism-focused strategies are adaptive (Oyserman, Kemmelmeier, \& Coon, 2002), which suggests that not only do people establish a sense of satisfaction from their personal and independent self-actualizations, but also from being interdependent with others. Social situations and the norms of society shape the cognition, affect, and behavior of a person. Therefore, the integration of externally derived motivation within the self can be a source of one's life satisfaction. Even if the intention to act is derived from sources external to the person, but when action is accepted as personally important, the regulation or control of behavior is more internal (Ryan \& Deci, 2000). 
The behavior is then more self-fulfilling, and satisfying. And because socially oriented motives are socially catalyzed (Chang \& Wong, 2008), they are more likely to contribute to life satisfaction among adolescents who are socialized with an interdependent view of the self. In a collectivist society where people hold an interdependent construal of the self (Markus \& Kitayama, 1991), like the Philippines, the endorsement of social goals may bring about positive emotions, and that these emotions further motivate the students to explore new objects and situations within their social environment (Fredrickson, 1998), thereby providing sustainable resources for their life satisfaction and well-being. Although the present study did dot test a causal relationship among the variables, the results suggest that social goals have a potential contribution to students' life satisfaction, which extends both the current theorizing of achievement motivation and the previous findings on the relationship of motivational processes on well-being (e.g., Lyubomirsky, 2001).

Just as health professionals encourage a greater reach for Positive Psychology to encourage a rethinking of interventions across diverse sociodemographic characteristics of people (Kobau et al., 2011), the present study also enhorts everyone in the helping profession, especially those who deal with students, to consider Positive Psychology as a tool for rethinking the structure and dynamics of achievement situations in school, the curriculum focus and its delivery, and other service programs to make the school an enabling institution for the enhancement of virtues and character strengths of students who will soon become active participants of the social enterprise within and beyond their professional areas.

\section{References:}

Blumenfeld, P. C. (1992). Classroom learning and motivation: Clarifying and expanding Goal Theory. Journal of Educational Psychology, 84, 272-281. http://dx.doi.org/10.1037/0022-0663.84.3.272

Burton, K. D., Lydon, J. E., D’Alessandro, D. U., \& Koestner, R. (2006). The differential effects of intrinsic and identified motivation on well-being and performance: Prospective, experimental, and implicit approaches to Self-Determination Theory. Journal of Personality and Social Psychology, 91, 750-762. http://dx.doi.org/10.1037/0022-3514.91.4.750

Chang, W. C., \& Wong, K. (2008). Socially oriented achievement goals of Chinese university students in Singapore: Structure and relationships with achievement motives, goals and affective outcomes. International Journal of Psychology, 43, 880-885. http://dx.doi.org/10.1080/00207590701836398

Dowson, M., \& McInerney, D. M. (2001). Psychological parameters of students' social and work avoidance goals: A qualitative investigation. Journal of Educational Psychology, 93, 35-42. http://dx.doi.org/10.1037/0022-0663.93.1.35

Dowson, M., \& McInerney, D. M. (2004). The development and validation of the goal orientation and learning strategies survey (GOALS-S). Educational and Psychological Measurement, 64, 290-310. http://dx.doi.org/10.1177/0013164403251335

Fredrickson, B. L. (1998). What good are positive emotions? Review of General Psychology, 2, 300-319. http://dx.doi.org/10.1037/1089-2680.2.3.300

Huebner, S. (2001). Manual for the Manual for the Multidimensional Students' Life Satisfaction Scale. Retrieved from http://www.psych.sc.edu/pdfdocs/huebslssmanual.doc

King, R. B., \& Watkins, D. A. (2011). Cross-cultural validation of the five-factor structure of social goals: A Filipino investigation. Journal of Psychoeducational Assessment, XX, 1-13.

Kobau, R., Seligman, M. E. P., Peterson, C., Diener, E., Zack, M. M., Chapman, D., \& Thompson, W. (2011). Mental health promotion in public health: Perspectives and strategies from Positive Psychology. American Journal of Public Health, 101, 1-9. http://dx.doi.org/10.2105/AJPH.2010.300083

Lammers, J., \& Stapel, D. A., (2009). How power influences moral thinking. Journal of Personality and Social psychology, 97, 279-289. http://dx.doi.org/10.1037/a0015437

Lyubomirsky, S. (2001). Why are some people happier than others? The role of cognitive and motivational processes in well- being. American Psychology, 56, 239-249.

http://dx.doi.org/10.1037/0003-066X.56.3.239 
Social goals of Filpino adolescents: Do they contribute to student life satisfaction?

Markus, H. R., \& Kitayama, S. (1991). Culture and the self: Implications for cognition, emotion and motivation. Psychological Review, 98, 224-253. http://dx.doi.org/10.1037/0033-295X.98.2.224

Mast, M. S., Jonas, K., \& Hall, J. A., (2009). Give a person power and he or she will show interpersonal sensitivity: The phenomenon and its why and when. Journal of Personality and Social Psychology, 97, 835-850. http://dx.doi.org/10.1037/a0016234

McNulty, J. K., \& Fincham, F. D. (2012). Beyond positive psychology? Toward a contextual view of psychological processes and well-being. American Psychologist, 67, 101-110. http://dx.doi.org/10.1037/a0024572

Oishi, S., Wyer, R. S. Jr., \& Colcombe, S. J. (2000). Cultural variation in the use of current life satisfaction to predict the future. Journal of Personality and Social Psychology, 78, 434-445.

http://dx.doi.org/10.1037/0022-3514.78.3.434

Ouano, J. A. (2011). Motivational antecedents of academic emotions in Filipino college students. The Asia-Pacific Education Researcher, 20, 127-132.

Ouano, J. A. (2012). Students' social reasons for doing schoolwork: Patterns across childhood and adolescence. Philippine Journal of Counseling Psychology, 14, 1-12.

Oyserman, D., Kemmelmeier, M., \& Coon, H. M. (2002). Cultural Psychology, A new look: Reply to Bond (2002), Fiske (2002), Kitayama (2002), and Miller (2002). Psychological Bulletin, 128, 110-117. http://dx.doi.org/10.1037/0033-2909.128.1.110

Ryan, R. M., \& Deci, E. L. (2000). Self-determination theory and the facilitation of intrinsic motivation, social development, and well-being. American Psychologist, 55, 68-78. http://dx.doi.org/10.1037/0003-066X.55.1.68

Seligman, M. E. P., \& Csikszentmihalyi, M. (2000). Positive Psychology: An introduction. American Psychologist, 55, 1-14. http://dx.doi.org/10.1037/0003-066X.55.1.5

Seligman, M. E. P., Steen, T. A., Park, N., \& Peterson, C. (2005). Positive Psychology progress: Empirical validation of interventions. American Psychologist, 60, 410-421. http://dx.doi.org/10.1037/0003-066X.60.5.410

Triandis, H. C. (1995). Motivation and achievement in collectivist and individualist cultures. In M. L. Maehr \& P. P. Pintrich (Eds.), Advances in motivation and achievement. Vol 9, pp. 1-30, CT: JAI Press Inc.

Urdan, T.C., \& Maehr, M.L. (1995). Beyond a two goal theory of motivation and achievement: A case for social goals. Review of Educational Research, 65, 213-243. 
Ouano, J. A. \& Pinugu, J. N. 